\title{
Factors That Affect Exercise Habits of College Students
}

\author{
Luke Eichorn ${ }^{1}$, Kayla Bruner ${ }^{2}$, Taylor Short ${ }^{3} \&$ Samuel P. Abraham ${ }^{4}$ \\ ${ }^{1}$ Emergency Department, Beacon Health, South Bend, Indiana, USA \\ ${ }^{2}$ Emergency Department, University of Toledo Medical Center, Toledo, Ohio, USA \\ ${ }^{3}$ Emergency Department, Augusta Health, Fishersville, Virginia, USA \\ ${ }^{4}$ Bethel College, Mishawaka, Indiana, USA \\ Correspondence: Samuel P. Abraham, Bethel College, School of Nursing, 1001 Bethel Circle, Mishawaka, \\ Indiana, 46545, USA.
}

Received: January 29, 2018

Accepted: February 17, 2018

Online Published: March 2, 2018

doi:10.20849/jed.v2i1.327

URL: https://doi.org/10.20849/jed.v2i1.327

\begin{abstract}
Various factors affect the exercise habits of college students. Some of these factors include sleep habits, diet, social life, homework, and other extracurricular activities. Although college students are aware of some of these influencing agents, they do not always take the necessary steps to change their habits. Exercise habits that an individual adheres to while in college would often determine their exercise habits for the rest of their lives. The purpose of this study was to determine the various factors that affect the exercise habits of college students. In this research, a convenience sample of 124 college students participated in a cross-sectional survey. The results indicated that the top reasons college students exercised was to remain healthy $(\mathrm{M}=3.42, \mathrm{SD}=0.64)$, to gain the positive feeling that comes from exercise $(\mathrm{M}=3.22, \mathrm{SD}=0.74)$; to join with friends who exercised $(\mathrm{M}=2.99$, $\mathrm{SD}=0.72)$; and when feeling overweight $(\mathrm{M}=2.96, \mathrm{SD}=0.88)$. Participants gave increased agreement to the item, "Having an increased homework load decreases the time I spend for exercise" $(\mathrm{M}=3.10, \mathrm{SD}=0.86)$. This study may be useful for educators to teach and inform college students on the factors that affect exercise habits. A recommendation is to promote time management skills that are intentional about leaving adequate time for exercise. Teaching students how to balance personal life, school, and work will leave more time for them to exercise, and therefore, increase their health overall. Based on the health belief model, both positive and negative self-perceptions are motivating factors that causes people to take necessary steps to stay healthy.
\end{abstract}

Keywords: exercise and motives, stressors and college students, stress and college students, exercise and college students

\section{Introduction}

The amount of exercise that a person gets is directly related to the well-being of that individual. For example, it has been shown that physical exercise reduces stress, improves mood, and helps to prevent obesity. Many students suffer from obesity, anxiety, depression, and other health conditions, which is partially because of their lack of exercise. Gates (2012) said, "If America's obesity trend continues at its current pace, all 50 states could have obesity rates above $44 \%$ by 2030 " (para. 1). Therefore, the purpose of this study was to determine the various factors that affect the exercise habits of college students.

\section{Background}

Barnett et al. (2013) affirmed, "The college years are a critical time for the development of positive and negative health behaviors that persist into later life" (p. 1134). It is important that college students need to be informed about the benefits of exercise early in their college life. What they do in their college years could potentially determine their habits for the rest of their lives; whether their lives will be active or sedentary. "There is evidence of a steep decline in physical activity through adolescence and young adulthood, and in 2012 at least $49 \%$ of over 90,000 college students did not meet national guidelines for exercise" (Barnett et al., 2013, p. 1134). When young people do not meet guidelines for exercise, they are opening themselves up to chronic diseases at an early age in life, which in turn may negatively affect their lives and the economy of countries.

In a cross-sectional study, Magaraggia, Dimmock, and Jackson (2014), investigated if motivational priming would affect exercise goals and engagement. In this study, 137 first-year college undergraduates participated; 
and they were divided into two groups. One group was told that the faculty of English and cultural studies was collecting normative data regarding comprehensive ability among college students. The second group received information that contained an overview of goal setting regarding exercise. The second group also received an outline that asked the students to set exercise goals for the following week. The results of the study indicated that there was a motivational component that could influence someone's exercise goals; specifically the goals on the duration of exercise. The frequency of exercise, unlike duration of exercise, was not found to be affected as much by motivation. Furthermore, the "perception of environmental stimuli can influence social behavior and judgment without a person's awareness of this influence" (Magaraggia et al., 2014, p. 826).

\section{Problem Statement}

Six in 10 college students do not get the recommended amount of physical exercise (Sparling, 2007). Lack of physical exercise can lead to some health issues including obesity, cardiovascular disease, and increased risk for cancer. In 2011, 29.2\% of college students were considered overweight (Anderson, 2012). These two alarming statistics emphasize the need for increased exercise on college campuses and, therefore, the need to study the factors that affect exercise habits of college students.

\section{Purpose Statement}

The purpose of this quantitative study was to determine the factors that affect the exercise habits of college students.

\section{Research Question}

One primary research question guided this study. The question assessed the participants' personal factors that affected their exercise habits. What are the factors affecting the exercise habits of college students?

\section{Review of the Literature}

\subsection{Database}

The following literature was obtained through the college library website. The search was conducted using the Cumulative Index of Nursing and Allied Health Literature (CINAHL) and EBSCOhost databases to search for peer-reviewed and evidence-based practice articles. Search phrases included exercise and motives, stressors and college students, stress and college students, and exercise and college students. The articles retrieved ranged in publication years from 2008 to 2014 . The studies were conducted on exercise and factors affecting exercise, of college students and were used to create a review of the literature for this study.

\subsection{Factors Affecting Exercise Habits}

Barry, Whiteman, Piazza-Gardner, and Jensen (2013) conducted both a qualitative and quantitative study about the relationship between exercise, weight loss, and alcohol use on college campuses. There were 26,062 (18,107 females and 7,955 males) participants in this study who came from 40 different college campuses across the United States. Some other variables were also considered such as race, the size of the campuses, the geographic location, and religious affiliation.

In the qualitative portion of this study, all participants were asked questions regarding the high number of calories in alcohol. Many participants expressed concern about calories consumed from alcohol and, as a result, many of them did some form of diet-related behaviors (Barry et al., 2013). The researchers suggested that "although it is known that alcohol use and eating behaviors exhibit a clear association, there is currently an emerging literature-base that links these behaviors to other (non-dietary) weight control practices such as exercise" (Barry et al., 2013, p. 407). The researchers also discovered that some college students are considered "weight-conscious drinkers," which means they will either restrict their diet after drinking to limit the number of calories consumed or exercise excessively to work off the calories from alcohol (Barry et al., 2013).

In the survey, there were a variety of quantitative questions which revealed that on average, college students did 3.42 days of moderate exercise, 2.66 days of vigorous exercise, and 2.18 days of strength-training over the past 7 days (Barry et al., 2013). Moderate exercise was defined as a noticeable increase in heart rate such as a brisk walk; vigorous exercise was defined as exercise that causes large increases in breathing or heart rate such as jogging, and strength training was defined as using a resistance weight machine. The researchers concluded that exercise can potentially increase alcohol use and can affect a person's body mass index. However, they also found that body mass index and the desire to lose weight could affect how much someone exercises. About gender differences, it was concluded that males are more likely to use exercise as a way to reduce weight, whereas females are more likely to use other means to lose weight (Barry et al., 2013).

In a qualitative study, Freene, Waddington, Chesworth, Davey, and Cochrane (2014) attempted to determine the 
barriers and enablers of middle-aged persons' exercise habits. The result indicated the unfortunate fact that "the incidence of chronic disease increases in middle-age (50-65 years old) and later years" (Freene et al., 2014, p. 85). The population in this study consisted of 158 middle-aged adults who lived in Australia. Of that population, 37 Physical Activity at Home (PAAH) attendees completed the Active Australia Survey (AAS) and were divided into three groups, which included group exercise program attendees $(n=14)$, group exercise program non-attendees $(\mathrm{n}=9)$, and home-based physical activity program attendees $(\mathrm{n}=14)$. For the study, the researchers considered four main themes: physical activity program enablers, physical activity program barriers, adherence to physical activity, and physical activity preferences. Although there was no direct theoretical framework used, the results indicated that the Self Determination Theory could have been a potential framework (Freene et al., 2014).

At the conclusion of their study, Freene et al. (2014) identified factors that act as barriers to exercise and factors that act as enablers to exercise. Factors that act as barriers to attending a group exercise program fall into four categories: gender-specific barriers, environmental barriers, program intervention barriers, and person-based barriers. An example of a gender-specific barrier was that women preferred, and were more likely to, exercise with other women, rather than if men were present in the program. Environmental barriers included work and career commitments, holidays, group scheduling conflicts, and weather. Program intervention barriers included that people did not find exercise "fun", there was a decreased awareness of program attendees' guidelines, group program types and intensity of exercise were too difficult, and expectations were not met. Person-based barriers included personal factors such as low self-efficacy, health problems, lack of social interaction, poor motivation, and low priority placed on the exercise program. The researchers suggested that enablers to adhering to exercise regimens included proximity of the exercise facility, easy parking at the work-out facility, no cost to the program, warm and inviting programs, and significant peer support (Freene et al., 2014).

In addition, Freene et al. (2014) discovered that many of the barriers to home-based physical activity programs were similar to those of group exercise programs; however, many of the enablers were different. The main enablers of home-based exercise programs were the flexibility of time, type of activity, and duration. Therefore, as this study indicated, there were many factors considered that motivated the middle-aged population to choose either a home-based exercise program or a group exercise program (Freene et al., 2014).

Tucker's (2014) study dealt with barriers to exercise compliance and how to accommodate and work with people who have barriers to exercise. Tucker stated, "Patient compliance goes up when patients know they are being 'watched' and retested" (p. 1). This phenomenon was then used in relation to exercise. If people know they are being watched and assessed during a workout, they will be more likely to workout harder and longer.

In one study, Tucker (2014) suggested three main steps for participants to follow to help motivate them to follow the recommended exercise routine. The first step was to establish specific goals. Examples of specific goals included such things as how many times per week someone would exercise and how long would be each exercise session. Within this first step, Tucker (2014) recommended that the participants set realistic goals to avoid being discouraged by not meeting impractical goals. The second suggested step was helping the participants be aware of their body. This step is so important because if participants are aware of their body's limits, they will be much less likely to over exercise. The third and final step suggested by Tucker was to organize an exercise program that was overseen by a healthcare provider. Tucker found participants who received specific feedback from the tests and programs they participated in were much more highly motivated. These steps were beneficial for the participants to determine and overcome barriers to their exercise habits.

In a qualitative study, Nabi and Thomas (2013) examined the effects of reality entertainment programming and embedded commercials on viewers' perceived motivations to exercise, consume a healthy diet, and preference of foods. In this study, "253 female undergraduates, [ages 18-23 years], were randomly assigned to watch an episode of a health-oriented reality program, a non-health-oriented reality program, or a health-themed sitcom in which commercials for either healthy or unhealthy goods were embedded" (Nabi \& Thomas, 2013, p. 699). In relation to ethnicity, the population was composed of $66 \%$ Caucasian, $13 \%$ Hispanic, $13 \%$ Asian-American, and $4 \%$ African-American. Furthermore, $82 \%$ of the participants were within the normal range of 18.5-24.9 for their body mass index (BMI). The three television programs used in this study included The Biggest Loser (health-oriented reality program), America's Toughest Jobs (non-health-oriented reality program), and The Office (health-oriented fictional program). Within each program, the researchers embedded nine ads, six of which were non-health based and three of which were health based (Nabi \& Thomas, 2013).

The participants watched an episode and then completed a post-test survey that measured emotional reactions to the program, perceived diet and exercise knowledge, motivation, and self-efficacy (Nabi \& Thomas, 2013). 
Participants were then asked to select a snack from six options. The researchers found that those who perceived the events in The Biggest Loser as more real had greater motivation to eat healthy (as was portrayed by them choosing a more healthy snack option), while the same motivation was not caused by the other two programs. Therefore, this study suggested that The Biggest Loser, and other programs similar to this, have the potential to boost key perceptions underlying behavior change (Nabi \& Thomas, 2013).

Barnett et al. (2013) investigated the association of peer behavior with alcohol use, marijuana use, and exercise in a college residence hall. This study was conducted by having 129 students in a residence hall perform an online survey that was based on substance abuse and exercise. The students identified ten individuals in their residence hall who were important to them (Barnett et al., 2013). They also used two social network analyses. Barnett et al. (2013) stated, "A social network analysis is a methodological and analytic approach that can be used to understand the risk and protective influences on individuals within a social context" (p. 1135). The social network analyses were used to identify peer groupings and to examine the associations between peer and participant behaviors (Barnett et al., 2013).

As a result of the study, Barnett et al. (2013) found that peer substance abuse was associated with that of participants, but peer exercise levels were not associated with exercise levels of participants. Therefore, they concluded that college student networks might be good targets for prevention programs. Programs that would influence close-proximity peers to influence the behaviors of others would be effective when dealing with substance abuse problems.

Egli, Bland, Melton, and Czech (2011) examined the influence that age, sex, and race had on college students' motivation to exercise. The method used in the study was a quantitative, cross-sectional descriptive research method. The participants were selected from a medium-sized southeastern university and included 2,199 students, of which 1,081 were men, and 1,118 were women. The study stemmed from the realization that obesity plays a major role in the decreasing health of our nation. Egli et al. noted that $24.2 \%$ of college students do not participate in moderate physical activity at all, and $41.4 \%$ do not participate in vigorous activity. The researchers pointed out that the motivation behind an action is what spurs people to that action; and henceforth, this study was conducted (Egli et al., 2011).

To gather the necessary data, Egli et al. (2011) used the Exercise Motivation Inventory-2 (EMI-2), which is a revised tool that uses psychometric measurements to analyze the motivations of both exercisers and non-exercisers. As a reminder, the study was completed to analyze the motivation to exercise related to sex, age, and race among college students. In the population that participated, $50.8 \%$ were female and, $49.2 \%$ were male; $63.4 \%$ were 19 years of age or younger and, $35.4 \%$ was 20 years of age or older; and $64.4 \%$ was white, while $21.7 \%$ were black. The EMI-2 scale consisted of 51 various items and 14 different smaller scales that participants responded to using a scale that utilized the numbers " 0 " to " 5 ", which represented "never true for me" and "always true for me" respectively (Egli et al., 2011).

Egli et al. (2011) found that the main exercise motivators were positive health and ill-health avoidance, followed closely by appearance, strength and endurance, and weight management. Although it is beneficial to view the results as a whole, it is also beneficial to view them independently by sex, age, and race. However, the only demographic group in which the results were slightly different was in the gender group. In this group, the results showed that men were more motivated by strength and endurance, followed by positive health, while women were motivated by positive health, followed by weight management. In conclusion, this study determined the main motivators for exercise for most college students, and the information was utilized to address the obesity issue at hand (Egli et al., 2011).

In a cross-sectional study, Graf and Welle (2014) attempted to determine the effectiveness of lifestyle habits and coping strategies on stress tolerance among college students. The researchers first had to develop and quantify the concept of "stress tolerance". In the study, "if a habit or coping strategy proves to be effective, it might be possible for college students to improve their stress tolerance rather than try to mediate stress once already overburdened" (Graf \& Welle, 2014, p. 97). During the study, these coping strategies were deemed effective if they were associated with high-stress tolerance. They used a cluster sampling technique to randomly select general classes and survey the students in those classes. There were 459 participants who completed the survey, all of whom were enrolled in a Healthful Living course at their university. The survey consisted of three pages that included the following: a checklist of major life events, a checklist of minor occurrences, and a stress symptom scale. The results of the study supported the previous research and found that college students were overwhelmed, suffered from emotional ups and downs, had difficulty falling asleep, and had feelings of anxiety (Graf \& Welle, 2014). 
Chu, Bushman, and Woodard (2008) used the Pearson product-moment correlation method to determine the "relationships among social physique anxiety, obligation to exercise, and exercise choices" (p. 7). The study arose out of a desire for health professionals to better encourage college students to fully participate and be committed to an exercise program. The study was completed using the following three scales: the Social Physique Anxiety Scale (SPAS), the Obligatory Exercise Questionnaire (OEQ), and the Physical Activity Specification Survey (PASS). Social physique anxiety was defined as the amount of anxiety a person receives from the way that others view their physical appearance (Chu et al., 2008). Obligatory exercise "refers to an individual's commitment to and involvement in exercise" (Chu et al., 2008, p. 7). The participants in the survey consisted of 337 individuals at a Midwestern university whose ages ranged from 18-33 years, of which 200 were women, and 137 were men. After giving informed consent, the participants were asked to fill out each of the three surveys in their entirety. The results of the SPAS indicated that women had more social physique anxiety than did men. The results of OEQ displayed that men and women had similar levels of obligation to exercise. Furthermore, the results showed a high relationship between the OEQ scores and the various components of PASS (Chu et al., 2008).

The objective of the study by Gruber (2008) was to determine the level of influence that both friend groups and peer groups had on the exercise and eating habits of college students. The problem that prompted the study was that more and more college students were gaining excess weight, which increased their chances of being obese later in life. Gruber (2008) then related this obesity problem to social influences because previous research has shown that college students often consider their peer and friend groups' opinions as more important than their families' opinions.

Gruber (2008) conducted a study using the 50-item Friend/Peer Support for Healthy Eating and Physical Activity Scale (FPS-HEPAS), with which participants were instructed to rate each question twice: once in relation to their friend group and once in relation to their peer group. The scale was a 5-point scale in which "4" represented "Very Often" and "0" represented "Never". There were 410 college students involved in this study, and all participants attended an African American university. There were 201 males and 219 females (ranging from 18 to 24 years of age) who were asked to take the FPS-HEPAS. Upon receiving all the completed surveys, the data were analyzed using principal component analysis methods (Gruber, 2008).

The Gruber (2008) study results indicated that females reported being more influenced by their peers about their exercising and eating habits. However, this support was not just positive support; it also included a higher level of negative support in relation to exercise. Furthermore, when the females' peer or friend groups were composed of mostly male members, the females felt as though they received both positive support for exercising and criticism for not exercising (Gruber, 2008). Similarly, males received the most support from their peer and friend groups when those groups were mostly female members. When it came to questions regarding their exercise habits, $39.4 \%$ of females exercised to lose weight, as opposed to only $20.4 \%$ of males; yet at the same time, $30.3 \%$ of females were likely not to exercise at all, as opposed to only $12.4 \%$ of males. It was concluded, "Females reported receiving greater support for their diet and exercise action than did males" (Gruber, 2008, p. 557).

\subsection{Summary of the Literature Review}

The above literature review was a thorough analysis of the information available to aid in the conduction of the study about the factors that affect the exercise habits of college students. Obesity, which is significantly related to lack of exercise, has unfortunately become a rising trend in our society, and the college years are perhaps the best time to begin forming those exercise habits that will help combat that trend in the future. Although the above studies approached the topic of exercise habits, or lack thereof, among college students in a myriad of ways, each study was found to be very beneficial in providing knowledge on this issue.

\section{Theoretical Framework}

The health belief model (HBM) was used to guide the research. The HBM elucidates that certain factors needed to be present for an individual to take action to avoid disease (Rosenstock, 1974). These factors influence the individual's perception and affect the likelihood of action. The relationship between the factors, individual's perceptions, and the likelihood of action are explained in the HBM.

The factors that need to be present for action include the belief that they were susceptible to that specific disease, that the disease would at least have moderate severity, that taking a certain action would be beneficial by reducing susceptibility or severity, and that it would not entail overcoming important psychological barriers (i.e., cost, convenience, pain, and embarrassment). Based on the HBM, there are five modifying factors in an individual's perception of health and self, which include the following: demographic variables such as age, sex, and race; socio psychological variables such as social class; knowledge of the disease; perceived threat of the 
disease; and cues to action (Rosenstock, 1974). Both positive and negative self-perceptions are motivating factors that causes people to take necessary steps to stay healthy.

\section{Definition of Terms}

A barrier to exercise is a hurdle that negatively affects an individual's amount of exercise. For example, no access to a workout facility would potentially decrease the amount of exercise performed. Factors that affect are defined as any circumstance that alters an outcome. An exercise habit is a tendency to perform a certain task during exercise. Moderate exercise is defined as an activity that increases the heart rate to $50-75 \%$ of the maximum heart rate. For example, if an individual has a maximum heart rate of $200 \mathrm{bpm}$, moderate exercise would be increasing the rate to between $100-150 \mathrm{bpm}$. Any strategy that effectively minimizes stress is known as coping strategy. Self-efficacy is defined as a person's perceived ability to perform and succeed in a task.

\section{Methodology}

\subsection{Method and Design Appropriateness}

The purpose of this study was to determine factors that affect college students' exercise habits. The method chosen was a survey using cross-sectional, non-experimental design. A quantitative approach was most appropriate because it allowed for more rapid data collection and provided information that could be analyzed in numbers.

\subsection{Population and Sampling Frame}

The participants in the study were college students. The participants were a convenience sample of 124 students. To enhance the study and increase randomization, all ethnicities, economic levels, and age groups were encouraged to participate.

\subsection{Geographic Location}

The geographical location for this study was outside the cafeteria on the college campus. This was a suitable location because many students use the building on a regular basis.

\subsection{Survey Instrument}

The survey instrument was a newly created instrument designed after a thorough review of the literature. The first six questions were demographic information followed by 20 items pertaining to potential effects on exercise The same instrument was given to each participant in a consistent method of instruction and direction for taking the survey. Within this survey were statements that pertained to factors that increase the amount someone would exercise or decrease the amount someone would exercise per week. All items were scored on a 4-point Likert-type scale based on levels of agreement ranging from " 1 " (strongly disagree) to "4" (strongly agree).

\subsection{Instrument Reliability and Validity}

To maintain the reliability of the instrument, the Likert-type scale items remained constant throughout the collection process. The survey tool has not been used in prior research studies and has not established research reliability; however, two peers and two college faculty members reviewed the questionnaire and provided feedback, which were implemented.

\section{Informed Consent and Confidentiality}

The informed consent given to each participant contained the purpose of the study along with the potential benefits. Each participant was given two copies, one to keep and one to sign and return before taking the survey. Once the consent was signed, it was placed in a manila envelope. After data analysis, the informed consent and completed surveys were stored safely. All collected data for this research was submitted to the College School of Nursing to be stored electronically for three years. The School of Nursing staff scanned the data into the computer and stored it on discs in a locked cabinet in a locked storage room. None other than the nursing administrators or the research coordinators have access to the stored records. By adhering to these guidelines, the participants' involvement was kept confidential.

\section{Results}

\subsection{Data Collection}

Permission was granted to survey in the lobby of the cafeteria to reach students going in or out. All researchers scheduled ahead of time to be present. Consents and the survey instruments were printed and arranged for data collection. After receiving approval from the Institutional Review Board, a suitable time for data collection was planned and implemented. As students passed by, they were asked if they would like to participate in the study. 
As they agreed, a consent form was given to each participant explaining the purpose of the study, stating that the study was optional and that they could withdraw at any time.

Once the consent form was signed, the participants were given the survey. The participants were also informed of confidentiality of the study, and upon completion, the surveys were placed in a manila envelope, separate from the consents. Involvement to take the survey was encouraged by offering store-bought all-natural fruit snacks as an incentive to complete the survey.

\subsection{Data Analysis}

The frequency and percentage were analyzed and described for the demographic data. The mean for each survey item and the standard deviation for each mean were calculated. The standard deviation provided a comparison between scores. A level of measurement for the questionnaire data was used because the survey was based on a Likert-type scale. The nominal level of measurement was used for the demographic data.

\subsection{Participants' Demographic Characteristics}

One-hundred and twenty-four individuals participated in this study, and all participants were college undergraduate students age 18 and older. Participants fully completed 124 surveys, allowing the use of those surveys for analysis. Table 1 contains descriptive statistics for the participants' demographics. The most common age ranges were age 18-24 (97\%), followed by age 25-31 (2\%), and age 32 and older (1\%). More females (53\%) were surveyed than males $(47 \%)$.

With a total sample size of 124 participants, the most common year in school was the senior year $(31 \%)$. The second most common year in school was the junior year (29\%), followed by participants in their freshman year $(24 \%)$. The least common year in school was the sophomore year (16\%). Among the surveyed, there were more non-varsity sports participants $(69 \%)$, than varsity athletes $(31 \%)$.

Of the participants surveyed, most had $16+$ credit hours (53\%), followed by $13-15$ credit hours $(35 \%), 10-12$ credit hours $(9 \%)$, and below 10 credit hours (3\%). Of those surveyed more said they exercised 4 or more hours per week (48\%). This was followed by 2 hours of exercise per week (19\%), less than 1 hour of exercise per week (13\%), 3 hours of exercise per week (12\%), and 1 hour of exercise per week (7\%).

Table 1. Demographic characteristics

\begin{tabular}{lll}
\hline Variable & $f$ & $\%$ \\
\hline Gender & 58 & $47 \%$ \\
Male & 66 & $53 \%$ \\
Female & & \\
Age Range: & 120 & $97 \%$ \\
$18-24$ & 3 & $2 \%$ \\
$25-31$ & 1 & $1 \%$ \\
$32+$ & & $24 \%$ \\
Year in School & 30 & $16 \%$ \\
Freshman & 20 & $29 \%$ \\
Sophomore & 36 & $31 \%$ \\
Junior & 38 & \\
Senior & & $31 \%$ \\
Play Varsity Sport & 38 & $69 \%$ \\
Yes & 86 & \\
No & & $3 \%$ \\
Registered Credits & 4 & $9 \%$ \\
Below 10 & 11 & \\
10-12 & & \\
\hline
\end{tabular}


Table 1 (continued). Demographic characteristics

\begin{tabular}{cll}
\hline Variable & $\boldsymbol{f}$ & $\mathbf{\%}$ \\
\hline $13-15$ & 43 & $35 \%$ \\
$16+$ & 66 & $53 \%$ \\
Hours of Exercise per week & & \\
$1<$ & 16 & $13 \%$ \\
1 & 9 & $7 \%$ \\
2 & 24 & $19 \%$ \\
3 & 15 & $12 \%$ \\
4 or more & 60 & $48 \%$
\end{tabular}

Description: $\mathrm{N}=124$.

\subsection{Results of Research Question}

The research question for this study reads, "What are the factors affecting the exercise habits of college students?" A 20-question survey was created to discover these factors, ten of which focused on psychosocial factors, six that focused on physical health factors, and four that were focused on other factors. Topics for psychosocial factors included positive feeling (Q 2), friends (Q 4), viewing oneself as overweight (Q 5), enjoyment (Q 6), social activities (Q 8), exercising with people (Q 10), looking good for others (Q 17), discomfort from exercise (Q 18), for others to notice (Q 19), and making up for lapse in academic performance (Q 20).

In addition to the 10 items about the psychosocial factors, six of the survey statements focused on physical health factors. Topics included remaining healthy (Q 1), noticing a weight gain (Q 7), keeping stomach trimmed (Q 9), maintaining current weight (Q 11), not eating healthy (Q 12), and decreasing weight (Q 13). The remaining four questions dealt with other factors that could potentially affect exercise habits. These included having an increased homework load (Q 3), bad weather (Q 14), winter months (Q 15), and having a test the next day (Q 16). The participants rated each item on a scale from 1 (Strongly Disagree) to 4 (Strongly Agree). In Table 2, the mean levels of agreement with the twenty questions about factors that affect exercise were ranked by level of agreement.

Table 2. Factors that affect exercise habits

\begin{tabular}{lcc}
\hline Variable & Mean & SD \\
\hline 1. I exercise because I want to remain healthy. & 3.42 & 0.64 \\
2. The positive feeling I get after I exercise causes me to exercise more. & 3.22 & 0.74 \\
3. Having an increased homework load decreases the time I spend on exercise. & 3.10 & 0.86 \\
4. When my friends exercise I am more likely to exercise. & 2.99 & 0.72 \\
5. Whenever I view myself as overweight, I exercise more. & 2.96 & 0.88 \\
6. Reason for my exercise is enjoyment. & 2.95 & 0.84 \\
7. Noticing a weight gain causes me to increase the frequency of exercise regimen. & 2.80 & 0.88 \\
8. I tend to get more exercise whenever there aren't many social activities. & 2.72 & 0.66 \\
9. I exercise to keep my stomach trimmed. & 2.66 & 0.74 \\
10. When I exercise, I exercise with at least one or more people. & 2.57 & 0.76 \\
11. I exercise to maintain my current weight. & 2.49 & 0.67 \\
12. I am more likely to exercise if I have not been eating healthy. & 2.48 & 0.76 \\
13. I exercise to decrease my weight. & 2.47 & 0.87 \\
14. Bad weather decreases my chances of exercising that day. & 2.47 & 0.80 \\
\hline
\end{tabular}


Table 2 (continued). Factors that affect exercise habits

\begin{tabular}{lcc}
\hline Variable & Mean & SD \\
\hline 15. My exercise frequency decreases during the winter months. & 2.46 & 0.83 \\
16. If I have a test the next day, I don't exercise that day. & 2.37 & 0.93 \\
17. I exercise so I can look better for others. & 2.34 & 0.80 \\
18. The discomfort I feel while exercising causes me to exercise less. & 2.13 & 0.72 \\
19. I exercise because I want others to notice me. & 1.87 & 0.72 \\
20. I exercise and build muscles to make up for the lapse in academic performance. & 1.83 & 0.79 \\
\hline
\end{tabular}

Description: $\mathrm{N}=124$. The participants rated each item on a scale from 1 (Strongly Disagree) to 4 (Strongly Agree).

\subsection{Summary of Results}

This section presented the collected data from the surveys and revealed various trends that helped answer the research question. The surveys were distributed to discover factors that affect the exercise habits of college students. With all the demographics considered, the findings revealed that most college students exercise because they want to remain healthy. The second main reasons that college students exercise is because of the positive feeling they get. The amount of homework they have hindered their exercise regimen had an overwhelmingly high agreement by the participants. From these three statements alone, it is already clear that there are a wide variety of factors that play into a college student's exercise habits.

In addition to the above findings, it was also revealed that there are trends in the factors that influence college students' exercise habits. For example, it was clear from the data that students exercise first, for physical health benefits, but many are also encouraged to exercise for psychosocial reasons. For example, Q 1 deals with a physical benefit for exercise: staying healthy. However, Q 2-6 are related to psychosocial benefits of exercising such as having a positive feeling or exercising more when friends exercise. Therefore, it appears that although the primary factor that influences college students to exercise is for the physical benefit, it is also implied that many students exercise as a result of psychosocial factors. These trends will be discussed further in the following section.

\section{Discussion}

Findings of this study on factors that affect exercise habits of college students were drawn from the 20-statement Likert-type scale survey. The top reasons college students exercise is to remain healthy $(\mathrm{M}=3.42)$, to gain the positive feeling that comes from exercise $(M=3.22)$, having friends that exercise $(M=2.99)$, and feeling overweight $(\mathrm{M}=2.96)$. In addition to the top four reasons that influence exercise, it was also discovered that college students exercise because they enjoy it $(M=2.95)$ and there is a lack of social activities $(M=2.72)$.

As was previously mentioned, there were 10 items that focused on the psychosocial factors affecting exercise, six focused on the physical factors, and four discussed other factors. Of the five items that ranked the highest mean, three of them were statements dealing with psychosocial issues, while only one dealt with a physical health factor and one with other factors. Therefore, although the highest mean item was related to a physical health factor, the majority of the highest-ranking items dealt with psychosocial factors. Hence, the implication from this is that most students are influenced more in their exercise habits by the psychosocial factors rather than by the physical health factors. This is an interesting finding because often people are encouraged to exercise because of the physical benefits that exercise holds.

Another implication of the study was that there are other factors that keep the college students from exercising. For example, having the third highest mean out of all the items was a statement about the amount of homework that students have to complete. It seems obvious that other factors that compete for a student's time will cause them to use less time for exercise. Time management may be an issue for this group. Therefore, perhaps another finding of this study is that students should be encouraged to prioritize the things that are competing for their time. While homework should be high on the priority list, perhaps other things that are demanding student's time should be reconsidered. There were some implications and findings from this survey, but perhaps the most significant finding is that students seemingly are influenced more by psychosocial factors than by any other factor. 
In summary, participants viewed remaining healthy as the leading reason to increase exercise $(\mathrm{M}=3.42)$. Participants saw the positive feeling that follows exercise $(M=3.22)$ as the second leading cause that positively influences their exercise habits. The third leading cause that increases the amount of exercise of students is having a friend who exercises as well $(\mathrm{M}=2.99)$. The participants viewed having an increased homework load as the leading factor that decreases the amount of exercise $(M=3.10)$ followed by bad weather $(M=2.47)$ and winter months $(\mathrm{M}=2.46)$, all of which decrease the amount of exercise that students participated.

\section{Implications}

The results from this study are helpful because they assess the main factors that influence college students to either exercise or not exercise. Once these factors are discovered, it is easier to alter the factors in such a way that will encourage more exercise and decrease the factors that hinder exercise. If used, the results may help students realize what is keeping them from exercising and, if corrected, will help lead to a healthier life.

Furthermore, another implication is that perhaps educational institutions should focus more on the psychosocial factors that affect exercise habits rather than focusing solely on the physical factors. This almost seems backward from popular belief; however, this study revealed that there seems to be more psychosocial factors affecting exercise habits than are given credit.

\section{Limitations}

The study occurred in a college with a student population of about 2000; of this 124 participated in the survey. A total of $31 \%$ of the participants were collegiate athletes who are required to exercise to maintain physical fitness for their chosen sport, and therefore, this may have given a false impression that college students are more active than is the reality. This was also a volunteer-based study; hence, it may have been difficult to get students who are less active to complete the survey because of possibly feeling self-conscious. Other limitations of this study included small sample size, limited geographical location, and similar educational backgrounds. Because the survey tool was new and had not been tested, the results may not be the best representation.

\section{Conclusions and Recommendations}

The first conclusion from this study is that remaining healthy, positive feelings and an increased homework load are the top three factors that affected the amount of exercise. This was supported partially by the literature. Secondly, psychosocial factors have a significant amount of influence on the amount of exercise that college students participate. This fact was evident because of the higher means for many of the psychosocial questions as opposed to the means related to the physical health questions.

Based on the findings, there is a need for education on the importance of exercise and about how beneficial exercise is for the body and the overall health of an individual. If students can grasp the importance of exercise at this point in their lives, it will set them up for healthier lives as they age. In addition, individuals should learn that their emotional health is enhanced with exercise and increased activity. Each recommendation relates to the original problem of the lack of exercise by young adults, particularly college students, and is an incentive for individuals to exercise more. Individuals of all ages should be encouraged to exercise to remain healthy, both physically and emotionally. A final recommendation is to promote time management skills that are very intentional about leaving adequate time for exercise. Teaching students how to balance personal life, school, and work will leave more time for them to exercise, and therefore, will increase their health overall.

One recommendation for a future research study is to have more participants complete the survey. Through having a larger sample size, the research may have more validity. This would also allow for a broader sample of people from different backgrounds, ages, and views on factors that are affecting the exercise habits of college students and adults in general.

Another recommendation is to conduct further research on this topic using the same survey as was used in the current study. Using the same research tool would allow the researchers to compare the results of this study to the results of their study. In addition, future research should be conducted with more non-athlete college students to get a better feel for the majority of the student body. A final recommendation would be to add a qualitative component to the study, which would encompass more of the student's behaviors and attitudes toward exercise.

\section{Acknowledgment}

The authors wish to acknowledge Dr. Deborah Gillum, Dean of Nursing, Bethel College, Mishawaka, Indiana, for offering valuable comments during the early stages of the study. We also like to thank Bethel College administrators for giving us the opportunity to conduct this study. 


\section{References}

Anderson, M. (2012). Don't become a statistic: Prevent obesity now. Retrieved from http://www.rasmussen.edu/degrees/health-sciences/blog/dont-become-a-statistic-prevent-obesity-now/

Barnett, N., Clark, M., Linkletter, C., Loxley, M., Rogers, M., \& Ott, M. (2013). Peer associations for substances use and exercise in a college student social network. Health Psychology, 33(10), 1134-1142. https://doi.org/10.1037/a0034687

Barry, A. E., Whiteman, S., Piazza-Gardner, A. K., \& Jensen, A. C. (2013). Gender differences in the associations among body mass index, weight loss, exercise, and drinking among college students. Journal of American College Health, 61(7), 407-413. https://doi.org/10.1080/07448481.2013.823973

Chu, H., Bushman, B. A., \& Woodard, R. J. (2008). Social physique anxiety, obligation to exercise, and exercise choices among college students. Journal of American College Health, 57(1), 7-14. https://doi.org/10.3200/JACH.57.1.7-14

Egli, T., Bland, H. W., Melton, B. F., \& Czech, D. R. (2011). Influence of age, sex, and race on college students' exercise motivation of physical activity. Journal of American College Health, 59(5), 399-406. https://doi.org/10.1080/07448481.2010.513074

Freene, N., Waddington, G., Chesworth, W., Davey, R., \& Cochrane, T. (2014). Community group exercise versus physiotherapist-led home-based physical activity program: Barriers, enablers and preferences in middle-aged adults. Physiotherapy Theory \& Practice, $30(2), \quad 85-93$. https://doi.org/10.3109/09593985.2013.816894

Gates, S. (2012). American obesity in 2030: Most U.S. residents will be obese within next 2 decades (PHOTOS). Retrieved

from http://www.huffingtonpost.com/2012/09/18/us-obesity-2030-americans-obese_n_1893578.html

Graf, H. M., \& Welle, P. D. (2014). Effective lifestyle habits and coping stress tolerance among college students. American Journal of Health Education, 42(2), 96-105. https://doi.org/10.1080/19325037.2011.10599177

Gruber, K. J. (2008). Social support for exercise and dietary habits among college students. Adolescence, 43(171), 557-575. Retrieved from http://web.a.ebscohost.com/ehost/detail/detail?vid=20\&sid=ee4838fc-b13c-4c7d-bc1b-0b375d26e2eb\%40s essionmgr4004\&hid=4104\&bdata=JnNpdGU9ZWhvc3QtbGl2ZQ\%3d\%3d\#db=cin20\&AN=2010113004

Magaraggia, C., Dimmock, J., \& Jackson, B. (2014). Motivational priming as a strategy for maximizing exercise outcome: effects on exercise goals and engagement. Journal of Sports Science, 32(9), 826-835. https://doi.org/10.1080/02640414.2013.862841

Nabi, R., \& Thomas, J. (2014). The effects of reality-based television programming on diet and exercise motivation and self-efficacy in young adults. Health Communication, 28(7), 699-708. https://doi.org/10.1080/10410236.2012.711510

Rosenstock, I. M. (1974). Historical origins of the health belief model. Health Education Monographs, 2(4). https://doi.org/10.1177/109019817400200403

Sparling, P. (2007). Obesity of campus. Preventing Chronic Disease, 4(3). Retrieved from http:.//www.cdc.gov/ped/issues/2007/jul/06_0142.htm

Tucker, J. (2014). Overcoming barriers to exercise compliance. Dynamic Chiropractic, 32(17), 1-30. Retrieved from http://dynamicchiropractic.com/mpacms/dc/article.php?id=57119

\section{Copyrights}

Copyright for this article is retained by the author(s), with first publication rights granted to the journal.

This is an open-access article distributed under the terms and conditions of the Creative Commons Attribution license (http://creativecommons.org/licenses/by/4.0/). 